\title{
JPN Guidelines for the management of acute pancreatitis: medical management of acute pancreatitis
}

\author{
Kazunori Takeda ${ }^{1}$, Tadahiro Takada ${ }^{2, *}$, Yoshifumi Kawarada ${ }^{3}$, Koichi Hirata $^{4}$, Toshihiko Mayumi ${ }^{5}$, \\ Masahiro Yoshida $^{2}$, Mino Sekimoto ${ }^{6}$, Masahiko Hirota ${ }^{7}$, Yasutoshi Kimura ${ }^{4}$, Shuji Isaji ${ }^{8}$, Masaru Koizumi ${ }^{9}$, \\ Maкото Otsuki ${ }^{10, * *}$, and Seiki Matsuno ${ }^{11, * * *}$ \\ ${ }^{1}$ Department of Surgery, National Hospital Organization Sendai Medical Center, 2-8-8 Miyagino, Miyagino-ku, Sendai 983-8520, Japan \\ ${ }^{2}$ Department of Surgery, Teikyo University School of Medicine, Tokyo, Japan \\ ${ }^{3}$ Ueno Municipal Hospital, Mie, Japan \\ ${ }^{4}$ First Department of Surgery, Sapporo Medical University School of Medicine, Hokkaido, Japan \\ ${ }^{5}$ Department of Emergency and Critical Care Medicine, Nagoya University Graduate School of Medicine, Nagoya, Japan \\ ${ }^{6}$ Department of Healthcare Economics and Quality Management, Kyoto University Graduate School of Medicine, Kyoto, Japan \\ ${ }^{7}$ Department of Gastroenterological Surgery, Kumamoto University Graduate School of Medical Science, Kumamoto, Japan \\ ${ }^{8}$ Department of Hepatobiliary Pancreatic Surgery and Breast Surgery, Mie University Graduate School of Medicine, Mie, Japan \\ ${ }^{9}$ Ohara Medical Center Hospital, Fukushima, Japan \\ ${ }^{10}$ Department of Gastroenterology and Metabolism, University of Occupational and Environmental Health, Japan, School of Medicine, \\ Kitakyushu, Japan \\ ${ }^{11}$ Division of Gastroenterological Surgery, Tohoku University Graduate School of Medicine, Sendai, Japan
}

\begin{abstract}
The basic principles of the initial management of acute pancreatitis are adequate monitoring of vital signs, fluid replacement, correction of any electrolyte imbalance, nutritional support, and the prevention of local and systemic complications. Patients with severe acute pancreatitis should be transferred to a medical facility where adequate monitoring and intensive medical care are available. Strict cardiovascular and respiratory monitoring is mandatory for maintaining the cardiopulmonary system in patients with severe acute pancreatitis. Maximum fluid replacement is needed to stabilize the cardiovascular system. Prophylactic antibiotic administration is recommended to prevent infectious complications in patients with necrotizing pancreatitis. Although the efficacy of the intravenous administration of protease inhibitors is still a matter of controversy, there is a consensus in Japan that a large dose of a synthetic protease inhibitor should be given to patients with severe acute pancreatitis in order to prevent organ failure and other complications. Enteral feeding is superior to parenteral nutrition when it comes to the nutritional support of patients with severe acute pancreatitis. The JPN Guidelines recommend, as optional measures, blood purification therapy and continuous regional arterial infusion

Offprint requests to: K. Takeda

* President, Japanese Society of Emergency Abdominal Medicine; President, Japanese Society of HepatoBiliary-Pancreatic Surgery; President, Asian-Pacific Hepato-Pancreato-Biliary Association

** Chairman, Intractable Pancreatic Disease Investigation and Research Group of the Japanese Ministry of Health, Labour, and Welfare

*** President, Japan Pancreas Society
\end{abstract}

of a protease inhibitor and antibiotics, depending on the patient's condition.

Key words Acute pancreatitis - Conservative management . Antibiotics $\cdot$ Nutritional support $\cdot$ Protease inhibitor

\section{Clinical questions}

CQ1. Is adequate fluid replacement crucial in the management of acute pancreatitis?

CQ2. Is pain control by analgesia crucial in acute pancreatitis?

CQ3. Are nasogastric suction and $\mathrm{H} 2$ blockers necessary?

CQ4. Is the continuous intravenous application of a large dose of a protease inhibitor useful for severe acute pancreatitis?

CQ5. Is enteral nutrition superior to total parenteral nutrition as nutritional support in severe acute pancreatitis?

CQ6. Is prophylactic antibiotic administration necessary for the prevention of infections in severe acute pancreatitis?

CQ7. Is blood purification therapy useful in severe acute pancreatitis?

CQ8. Does continuous regional arterial infusion of protease inhibitors and antibiotics reduce the mortality rate and incidence of infectious complications in acute necrotizing pancreatitis? 


\section{Introduction}

In $70 \%$ to $80 \%$ of patients with acute pancreatitis, the disease is mild and promptly responds to supportive measures alone. The remaining $20 \%-30 \%$ of patients have a severe form of pancreatitis and develop shock, respiratory failure, and infectious complications. Patients with severe acute pancreatitis should be transferred to a medical facility where adequate monitoring and intensive medical care is available. ${ }^{1}$

The basic principles of the initial management of acute pancreatitis are adequate monitoring of vital signs, fluid replacement, correction of any electrolyte imbalance, nutritional support, and the prevention of local and systemic complications. In mild acute pancreatitis, adequate fluid replacement, pain relief, and monitoring of vital signs is enough to ensure recovery from the disease. In severe acute pancreatitis, strict cardiovascular and respiratory monitoring is mandatory for maintaining the cardiopulmonary system. Maximum fluid replacement is needed to stabilize the cardiovascular system, and adjustment of any electrolyte and acid-base imbalance is also required. Oxygen is administered, as needed, to maintain at least $95 \%$ oxygen saturation. Prophylactic antibiotic administration is recommended to prevent infectious complications in patients with necrotizing pancreatitis. Although the efficacy of intravenous protease inhibitor administration is still a matter of controversy, there is a consensus in Japan that a large dose of a synthetic protease inhibitor should be given to patients with severe acute pancreatitis in order to prevent organ failure and other complications. Nutritional support is crucial in patients with severe acute pancreatitis. Enteral feeding is superior to parenteral nutrition for the nutritional management of patients with severe acute pancreatitis.

\section{Principles of medical management for acute pancreatitis}

Clinical question (CQ) 1. Is adequate fluid replacement crucial in the management of acute pancreatitis?

An adequate volume of intravenous fluid should be promptly administered to correct the volume deficit and maintain basal fluid requirements (Recommendation A)

Increased vascular permeability in acute pancreatitis causes the loss of intravenous fluid and reduces plasma volume. In severe cases, in patients with massive ascites, pleural effusion, and retroperitoneal and mesenteric edema, circulating plasma volume decreases markedly. Hypovolemia may lead to shock and acute renal failure, and, because hypovolemic shock may impair the pan- creatic microcirculation and promote pancreatic ischemia and necrosis, restoration and maintenance of plasma volume is crucial in severe acute pancreatitis.

An adequate volume of intravenous fluid should be promptly administered to correct the volume deficit and maintain basal fluid requirements. Balanced electrolyte solutions, such as Ringer's lactate, are recommended to stabilize the cardiovascular system. The infusion volume should be decided while monitoring blood pressure, heart rate, hematocrit, and urine output. Calcium and potassium chloride should be replaced if deficiencies arise. Hyperglycemia is managed with insulin as needed. In patients with severe acute pancreatitis, continuous monitoring of central venous pressure or pulmonary wedge pressure, blood gas analysis, and electrolyte measurement is crucial to determining the adequate volume that must be replaced. Oxygen is administered as needed to maintain at least $95 \%$ oxygen saturation. Fluid infusion may be complicated by pulmonary edema due to an increase in lung water and is an indication for artificial ventilation.

CQ2. Is pain control by analgesia crucial in acute pancreatitis?

Acute pancreatitis is accompanied by persistent severe abdominal pain. Analgesia is crucial (Recommendation A)

The pain associated with acute pancreatitis may cause anxiety in patients and adversely affect their clinical course; this may include respiratory distress, which should be relieved shortly after it develops. The nonnarcotic analgesic buprenorphine has an effect superior to procaine, and, unlike procaine, it does not exacerbate the pathology of acute pancreatitis by including contracting the sphincter of Oddi (Level 1b). ${ }^{2}$ Buprenorphine has an analgesic effect similar to that of pethidine (Level1b). ${ }^{3}$

CQ3. Are nasogastric suction and $\mathrm{H} 2$ blockers necessary?

Nasogastric suction through a nasogastric tube is unnecessary in patients with acute pancreatitis unless the disease is associated with paralytic ileus and/or frequent vomiting. $\mathrm{H} 2$ blockers are also unnecessary unless a stress ulcer develops (Recommendation D)

There are no definitive studies in humans to support the opinion that nasogastric suction is useful to the pancreas at rest in patients with acute pancreatitis. Randomized controlled trials (RCTs) in patients with mild to moderate acute pancreatitis have shown no ameliorating effect of gastric suction on the clinical course by, for example, alleviating pain or shortening the hospital stay. ${ }^{4-11}$ Rather, there are some reports claiming that 
nasogastric suction may prolong the period of abdominal pain and nausea. ${ }^{7-10}$ The placement of a nasogastric tube in patients with acute pancreatitis is unnecessary unless the disease is associated with paralytic ileus and/ or frequent vomiting. There are no reports suggesting that cimetidine, an $\mathrm{H} 2$ blocker, might ameliorate the clinical course of acute pancreatitis: ${ }^{10,12-15}$ however, treatment with an $\mathrm{H} 2$ blocker should be considered when a patient with acute pancreatitis develops a stress ulcer or acute gastric mucosal lesion.

CQ4. Is the continuous intravenous application of a large dose of a protease inhibitor useful for severe acute pancreatitis?

Continuous intravenous infusion of a large dose of a protease inhibitor reduces the incidence of complications in the early phase of severe acute pancreatitis (Recommendation B)

In the 1960s, the protease inhibitor aprotinin was widely used to treat severe acute pancreatitis, but the drug failed to demonstrate clinical efficacy in three RCTs (Level 1b). ${ }^{16-18}$ The efficacy of the synthetic protease inhibitor gabexate mesilate was investigated in five RCTs (Level 1b), ${ }^{19-23}$ but a metaanalysis ${ }^{24}$ of four of them ${ }^{19-22}$ showed no reduction in the frequency of surgical intervention or in the mortality rate, although the incidence of complications was reduced (Level 1a). However, the remaining RCT (Level 1b), ${ }^{23}$ the results of which were published in 2000 , showed that continuous intravenous administration of gabexate mesilate $(2400 \mathrm{mg} /$ day $)$ for 7 days significantly reduced the frequency of complications and the mortality rate. Although the efficacy of protease inhibitors in severe acute pancreatitis is still a matter of controversy, the consensus in Japan, as outlined in the JPN Guidelines, recommends the continuous infusion of an intravenous protease inhibitor in the early phase of severe acute pancreatitis. Nafamostat mesilate (NM), a synthetic serine protease inhibitor, and gabexate mesilate (GM) are widely used in Japan. NM has a longer half-life than GM ( 55 s for GM vs 23 min for NM) and is used in patients with disseminated intravasucular coagulation (DIC) and during hemodialysis, because of its potent anti-coagulant effect.

CQ5. Is enteral nutrition superior to total parenteral nutrition as nutritional support in severe acute pancreatitis?

Enteral nutrition starting in the early phase of severe acute pancreatitis is superior to total parenteral nutrition unless ileus is present (Recommendation A)

There is no evidence from human studies to show that parenteral nutrition is clinically more efficacious in acute pancreatitis than enteral nutrition. Recent clinical trials of nutritional management in acute pancreatitis have shown that enteral nutrition is more useful than total parenteral nutrition in terms of ability to alleviate the inflammatory response and reduce the incidence of infection, frequency of surgery, and medical costs. A metaanalysis (Level 1a) ${ }^{31}$ of six RCTs (263 cases; Level 1b) ${ }^{25-30}$ - which compared two methods of nutritional management of acute pancreatitis (total parenteral nutrition and enteral nutrition) - showed that enteral nutrition reduced the frequency of infection, surgery, and the length of hospital stay. However, there was no difference in the mortality rate or incidence of complications other than infection.

Enteral nutrition has been provided through feeding tubes inserted from the ligament of Treitz to the distal jejunum, and the infusion of nutrients into the stomach and duodenum has been avoided because of the possibility of stimulating pancreatic exocrine secretion. However, a report from Glasgow (Level 1b), ${ }^{32}$ comparing nasogastric to nasojejunal feeding, found no difference in changes in the Acute Physiology and Chronic Health Evaluation (APACHE) II score, C-reactive protein (CRP) level, visual analogue scale (VAS) pain score, doses of analgesic administered, or mortality rates between the two methods. Nasogastric feeding is easier to perform and it is easier to locate the tube than it is to locate a nasojejunal tube. Nasogastric nutrition should be investigated further.

CQ6. Is prophylactic antibiotic administration necessary for the prevention of infection in severe acute pancreatitis?

Prophylactic administration of broad-spectrum antibiotics with good tissue penetration is necessary to prevent infection in severe acute pancreatitis (Recommendation A)

Pancreatic and extrapancreatic infections are a determining factor leading to death in severe acute pancreatitis. The mortality rate of patients with infected pancreatic necrosis or sepsis is extremely high, and antibiotic prophylaxis has been recommended to prevent infectious complications in severe acute pancreatitis. Three RCTs of the antibiotic ampicillin conducted in the 1970s showed that it did not reduce the frequency of infectious complications (Level 1b). ${ }^{33-35}$ A human study investigating pancreatic tissue penetration by antibiotics demonstrated that broad-spectrum antibiotics such as ciprofloxacin, ofloxacin, imipenem, and pefloxacin provided sufficient tissue concentration in the pancreas. ${ }^{36}$ Four RCTs (Level 1b) ${ }^{37-40}$ of the prophylactic effect of antibiotics demonstrated that broadspectrum antibiotics with good pancreatic tissue penetration decreased the incidence of infectious complications and 
the mortality rate. A metaanalysis of those RCTs showed that prophylactic antibiotic administration significantly improved the mortality rate in patients with severe acute pancreatitis (Level 1a). ${ }^{41}$ An RCT comparing pefloxacin with imipenem reported that imipenem significantly lowered the incidence of pancreatic infection (Level 1b). ${ }^{42}$ An RCT investigating the usefulness of prophylactic imipenem administration within $48 \mathrm{~h}$ after onset showed that the early administration of imipenem decreased the frequency of surgical intervention and the number of organs that failed (Level 1b). ${ }^{43}$ A comparison between meropenem and imipenem showed no difference in the occurrence of pancreatic infection, complications, or mortality rates (Level 1b). ${ }^{44}$ On the other hand, a placebo-controlled, double-blind trial of ciprofloxacin + metronidazole in patients with predicted severe acute pancreatitis showed that prophylactic administration of these antibiotics did not prevent pancreatic infection (Level 1b). ${ }^{45}$

Selective digestive decontamination (SDD) has also been reported as a means of antibiotic prophylaxis in severe acute pancreatitis (Level 1b) ${ }^{46}$ Although SDD was reported in the 1980s as a method of preventing respiratory tract infection in patients with multiple trauma, ${ }^{47}$ only one RCT assessed SDD in severe acute pancreatitis. ${ }^{46}$ In that trial, antibiotics were given orally, enterally, and intravenously, as well as being applied topically to the gums and tracheotomy site. SDD significantly reduced the frequency of infectious pancreatic complications compared with that in the control groups, and multivariate analysis with severity assessment demonstrated a reduced mortality rate for SDD. In principle, SDD offers comprehensive infection management, not only by the enteral administration of nonabsorptive agents but also by the prevention of systemic infection through sterilization of the oral cavity, as well as by intravenous antibiotic administration and continuous surveillance cultures of the oral cavity and rectum.

Although the prophylactic application of broadspectrum antibiotics reduces the incidence of infectious complications in severe acute pancreatitis, fungal infection in pancreatic necrosis is increasing. ${ }^{48-53}$ The mortality rate of infected pancreatic necrosis complicated by fungal infection is higher than the mortality rate in the absence of fungal infection (Level 2b). ${ }^{48-53} \mathrm{~A}$ human study reported that the antifungal agent fluconazole had good penetration into pancreatic tissue (Level 2b), ${ }^{54}$ and clinical studies have demonstrated that the prophylactic administration of fluconazole reduced the incidence of fungal infection in patients with severe acute pancreatitis (Level 2b). ${ }^{52-55}$ However, there have been no reliable RCTs of the prophylactic administration of antifungal agents in patients with pancreatic necrosis, and the efficacy of antifungal agents has yet to be investigated in an RCT.
CQ7. Is blood purification therapy useful in severe acute pancreatitis?

Blood purification therapy may prevent the development of multiple organ failure in severe acute pancreatitis (Recommendation C)

The activation of proinflammatory cytokines in severe acute pancreatitis is a predominant factor leading to multiple organ failure. Blood purification therapy, particularly continuous hemodiafiltration (CHDF), should inhibit the systemic inflammatory response by removing humoral mediators. CHDF with a polymethylmethacrylate (PMMA) membrane removes various cytokines from the bloodstream and is widely used in Japan for blood purification therapy in patients with severe acute pancreatitis complicated by multiple organ failure. A national survey of the usefulness of CHDF in severe acute pancreatitis suggested that it may prevent the progress of multiple organ failure,${ }^{56}$ but its ability to reduce the mortality rate is still unknown.

CQ8. Does continuous regional arterial infusion of protease inhibitors and antibiotics reduce the mortality rate and incidence of infectious complications in acute necrotizing pancreatitis?

Continuous regional arterial infusion of protease inhibitors and antibiotics may possibly reduce the mortality rate and incidence of infectious complications in necrotizing pancreatitis (Recommendation C)

The protease inhibitors used to treat acute necrotizing pancreatitis cannot easily reach the pancreas when administered intravenously, and, because of ischemia ${ }^{57,58}$ or impaired microcirculation, they hardly penetrate into pancreatic tissue. Administration through a catheter placed in one of the arteries that supply the inflamed area of the pancreas, however, dramatically increases the tissue concentration of the protease inhibitor. A clinical study of continuous regional arterial infusion (CRAI) of a protease inhibitor and/or an antibiotic demonstrated that CRAI of nafamostat mesilate and imipenem/cilastatin was effective in reducing the mortality rate and preventing the development of pancreatic infection in acute necrotizing pancreatitis. ${ }^{59} \mathrm{~A}$ nationwide survey of CRAI therapy in acute necrotizing pancreatitis reported that severe pain disappeared in a short period of time after the initiation of CRAI of a protease inhibitor; that the frequency of infected pancreatic necrosis in the group treated with both a protease inhibitor and antibiotic via CRAI was significantly lower than that in the group treated with the protease inhibitor alone; and that the mortality rate was significantly lower in the group in which CRAI of the protease inhibitor was started within 2 days after onset than that 
in the group in which it was started 3 or more days after onset. ${ }^{60} \mathrm{~A}$ historical study, comparing intravenous administration and CRAI of a protease inhibitor and antibiotic, revealed a significantly higher cumulative survival rate in the CRAI group. ${ }^{61}$ In a clinical study in which arterial infusion was performed after confirming, by computed tomography (CT) arteriography, that the drug had reached the site of inflammation in the pancreas, the APACHE II score and the CT severity index were improved in all subjects. ${ }^{62}$ CRAI of the protease inhibitor nafamostat also prevented pancreatic necrosis in patients with severe acute pancreatitis associated with nonocclusive mesenteric ischemia (NOMI). ${ }^{63} \mathrm{Al}-$ though the efficacy of CRAI of a protease inhibitor and the optimal timing is still being debated, CRAI therapy is given Recommendation C in the JPN Guidelines. The usefulness of CRAI of a protease inhibitor should be investigated further.

\section{References}

1. Mayumi T, Ura H, Arata S, Kitamura N, Kiriyama I, Shibuya K, et al. Evidence-based clinical practice guidelines for acute pancreatitis: proposals. J Hepatobiliary Pancreat Surg 2002;9:413-22.

2. Jakobs R, Adamek AC, von Bubnoff AC, Riemann JF. Buprenorphine or procaine for pain relief in acute pancreatitis. A prospective randomized study. Scand J Gastroenterol 2000;12: 1319-23.

3. Blamey SL, Finlay IG, Carter DC, Imrie CW. Analgesia in acute pancreatitis: comparison of buprenorphine and pethidine. BMJ 1984;288:1494-5.

4. Levant JA, Secrist DM, Resin H, Sturdevant RA, Guth PH. Nasogastric suction in the treatment of alcoholic pancreatitis. A controlled study. JAMA 1974;229:51-2.

5. Naeije R, Salingret E, Clumeck N, De Troyer A, Devis G. Is nasogastric suction necessary in acute pancreatitis? BMJ 1978;2:659-60.

6. Field BE, Hepner GW, Shabot MM, Schwartz AA, State D, Worthen N, et al. Nasogastric suction in alcoholic pancreatitis. Dig Dis Sci 1979;24:339-44.

7. Fuller RK, Loveland JP, Frankel MH. An evaluation of the efficacy of nasogastric suction treatment in alcoholic pancreatitis. Am J Gastroenterol 1981;75:349-53.

8. Loiudice TA, Lang J, Mehta H, Banta L. Treatment of acute alcoholic pancreatitis: the roles of cimetidine and nasogastric suction. Am J Gastroenterol 1984;79:553-8.

9. Sarr MG, Sanfey H, Cameron JL. Prospective, randomized trial of nasogastric suction in patients with acute pancreatitis. Surgery 1986;100:500-4.

10. Navarro S, Ros E, Aused R, Garcia Puges AM, Pique JM, Vilar Bonet J. Comparison of fasting, nasogastric suction and cimetidine in the treatment of acute pancreatitis. Digestion 1984;30:224-30.

11. Goff JS, Feinberg LE, Brugge WR. A randomized trial comparing cimetidine to nasogastric suction in acute pancreatitis. Dig Dis Sci 1982;27:1085-8.

12. Meshkinpour H, Molinari MD, Gardner L, Berk JE, Hoehler FK. Cimetidine in the treatment of acute alcoholic pancreatitis. A randomized, double-blind study. Gastroenterology 1979;77:68790.

13. Broe PJ, Zinner MJ, Cameron JL. A clinical trial of cimetidine in acute pancreatitis. Surg Gynecol Obstet 1982;154:13-6.
14. Goff JS, Feinberg LE, Brugge WR. A randomized trial comparing cimetidine to nasogastric suction in acute pancreatitis. Dig Dis Sci 1982;27:1085-8.

15. Loiudice TA, Lang J, Mehta H, Banta L. Treatment of acute alcoholic pancreatitis: the roles of cimetidine and nasogastric suction. Am J Gastroenterol 1984;9:553-8.

16. Skyring A, Singer A, Tornya P. Treatment of acute pancreatitis with Trasylol: report of a controlled therapeutic trial. BMJ 1965:2:627-9.

17. Baden H, Jordal K, Lund F, Zachariae FA. Double-blind controlled clinical trial of Trasylol. Preliminary results in acute pancreatitis and in prophylaxis against postoperative pancreatitis. Acta Chirurg Scand 1967; Suppl 378:97-102.

18. Imrie CW, Benjamin IS, Ferguson JC, McKay AJ, Mackenzie I, O'Neill J, et al. A single-centre double-blind trial of Trasylol therapy in primary acute pancreatitis. Br J Surg 1978;65:337-41.

19. Valderrama R, Perez MM, Navarro S, Vazquez N, Sanjose L, Adrian MJ, et al. Multicenter double-blind trial of gabexate mesilate (FOY) in unselected patients with acute pancreatitis. Digestion 1992;51:65-70.

20. Yang CY, Chang CC, Liaw YF. Controlled trial of protease inhibitor gabexelate mesilate (FOY) in the treatment of acute pancreatitis. Pancreas 1987;2:698-700.

21. Buchler M, Malfertheiner P, Uhl W, Scholmerich J, Stockmann F, Adler G, et al. Gabexate mesilate in human acute pancreatitis. German Pancreatitis Study Group. Gastroenterology 1993;104: 1165-72.

22. Dervenis C, Johnson CD, Bassi C, Bradley E, Imrie CW, McMahon MJ, et al. Diagnosis, objective assessment of severity, and management of acute pancreatitis. Santorini Consensus Conference. Int J Pancreatol 1999;25:195-210.

23. Chen HM, Chen JC, Hwang TL, Jan YY, Chen MF. Prospective and randomized study of gabexate mesilate for the treatment of severe acute pancreatitis with organ dysfunction. Hepatogastroenterology 2000;47:1147-50.

24. Andriulli A, Leandro G, Falconi M, Festa V, Caruso N, Annese $\mathrm{V}$, et al. Meta-analysis of somatostatin, octreotide and gabexate mesilate in the therapy of acute pancreatitis. Aliment Pharmacol Ther 1998;12:237-45.

25. McClave SA, Greene LM, Snider HL, Makk LJK, Cheadle WG, Owens NA, et al. Comparison of the safety of early enteral versus parenteral nutrition in mild acute pancreatitis. J Parent Ent Nutr 1997;21:14-20.

26. Windsor ACJ, Kanwar S, Li AGK, Barnes E, Guthrie JA, Spark JI, et al. Compared with parenteral nutrition, enteral feeding attenuates the acute phase response and improves disease severity in acute pancreatitis. Gut 1998;42:431-5.

27. Kalfarentzos F, Kehagias J, Mead N, Gogos CA. Enteral nutrition is superior to parenteral nutrition in severe acute pancreatitis: results of a randomized prospective trial. Br J Surg 1997;84:16659.

28. Olah A, Pardavi G, Belagyi T, Issekutz A, Mohamed GF. Early naso-jejunal feeding in acute pancreatitis is associated with a lower complication rate. Nutrition 2002;18:259-62.

29. Abou-Assi S, Craig K, O'Keefe SJ. Hypocaloric jejunal feeding is better than total parenteral nutrition in acute pancreatitis: results of a randomized comparative study. Am J Gastroenterol 2002:97:2255-62.

30. Gupta R, Patel K, Calder PC, Yaqoob P, Primrose JN, Johnson $\mathrm{CD}$. A randomized clinical trial to assess the effect of total enteral and total parenteral nutrition support on pancreatitis (APACHE II >6). Pancreatology 2003;3:406-13.

31. Marik PE, Zaloga GP. Meta-analysis of parenteral nutrition versus enteral nutrition in patients with acute pancreatitis. BMJ 2004;328:1407-13.

32. Eatock FC, Chong P, Menezes N, Murray L, McKay CJ, Carter $\mathrm{CR}$, et al. A randomized study of early nasogastric versus nasojejunal feeding in severe acute pancreatitis. Am J Gastroenterol 2005;100:432-9. 
33. Craig RM, Dordal E, Myles L. The use of ampicillin in acute pancreatitis. Ann Intern Med 1975;83:831-2.

34. Howes R, Zuidema GD, Cameron JL. Evaluation of prophylactic antibiotics in acute pancreatitis. J Surg Res 1975;18:197-200.

35. Finch WT, Sawyers JL, Schenker S. A prospective study to determine the efficacy of antibiotics in acute pancreatitis. Ann Surg 1976;183:667-71.

36. Buchler M, Malfertheiner P, Friess H, Isenmann R, Vanek E, Grimm H, et al. Human pancreatic tissue concentration of bactericidal antibiotics. Gastroenterology 1992;103:1902-8.

37. Pederzoli P, Bassi C, Vesentini S, Campedelli A. A randomized multicenter clinical trial of antibiotic prophylaxis of septic complications in acute necrotizing pancreatitis with imipenem. Surg Gynecol Obstet 1993;176:480-3.

38. Sainio V, Kemppainen E, Puolakkainen P, Taavitsainen M, Kivisaari L, Valtonen V, et al. Early antibiotic treatment in acute necrotising pancreatitis. Lancet 1995;346:663-7.

39. Delcenserie R, Yzet T, Ducroix JP. Prophylactic antibiotics in treatment of severe acute alcoholic pancreatits. Pancreas 1996;13:198-201.

40. Schwarz M, Isenmann R, Meyer H, Beger HG. Antibotika bei nekrotisierender pancreatitis. Ergebnisse einer kontrollierten studie. Dtsch Med Wochenschr 1997;122:356-61.

41. Golub R, Siddiqi F, Pohl D. Role of antibiotics in acute pancreatitis: a meta-analysis. J Gastrointest Surg 1998;2:496-503.

42. Bassi C, Falconi M, Talamini G, Uomo G, Papaccio G, Dervenis $\mathrm{C}$, et al. Controlled clinical trial of pefloxacin versus imipenem in severe acute pancreatitis. Gastroenterology 1998;115:1513-7.

43. Nordback I, Sand J, Saaristo R, Paajanen H. Early treatment with antibiotics reduced the need for surgery in acute necrotizing pancreatitis - a single-center randomized study. J Gastrointest Surg 2001;5:113-8.

44. Manes G, Rabitti PG, Menchise A, Riccio E, Balzano A, Uomo G. Prophylaxis with meropenem of septic complications in acute pancreatitis: a randomized, controlled trial versus imipenem. Pancreas 2003;27:e79-e83.

45. Isenmann R, Runzi M, Kron M, Kahl S, Kraus D, Jung N, et al. German Antibiotics in Severe Acute Pancreatitis (ASAP) Study Group. Prophylactic antibiotic treatment in patients with predicted severe acute pancreatitis: a placebo-controlled, doubleblind trial. Gastroenterology 2004;126:997-1004.

46. Luiten EJ, Hop WC, Lange JF, Bruining HA. Controlled clinical trial of selective decontamination for the treatment of severe acute pancreatitis. Ann Surg 1995;222:57-65.

47. Stoutenbeek CP, van Saene HK, Miranda DR, Zandstra DF. The effect of selective decontamination of the digestive tract on colonisation and infection rate in multiple trauma patients. Intensive Care Med 1984;10:185-92.

48. Grewe M, Tsiotos GG, Luque de-Leon E, Saar G. Fungal infection in acute necrotizing pancreatitis. J Am Coll Surg 1999;188:408-14.

49. Gotinger P, Wamser P, Barlan M, Sautner T, Jakesz R, Fugger R. Candida infection of local necrosis in severe acute pancreatitis is associated with increased mortality. Shock 2000;14:320-3.
50. Gloor B, Muller CA, Worni M, Stahel PF, Redaelli C, Uhl W, et al. Pancreatic infection in severe pancreatitis. The role of fungus and multiresistant organisms. Arch Surg 2001;136:592-6.

51. Isenmann R, Schwarz M, Rau B, Trautmann M, Schober W, Med $\mathrm{C}$, et al. Characteristics of infection with candida species in patients with necrotizing pancreatitis. World J Surg 2002;25:372-6.

52. De Waele JJ, Vogelaers D, Blot S, Colardyn F. Fungal infections in patients with severe acute pancreatitis and the use of prophylactic therapy. CID 2003;37:208-13.

53. Conner S, Alexakis N, Neal T, Raraty M, Ghaneh P, Evans J, et al. Fungal infection but not type of bacterial infection is associated with a high mortality in primary and secondary infected pancreatic necrosis. Dig Surg 2004;21:297-304.

54. Shrikhande S, Friess $\mathrm{H}$, Issengger $\mathrm{C}$, Martignoni $\mathrm{M}$, Yong $\mathrm{H}$, Gloor B, et al. Fluconazole penetration into the pancreas. Antimicrob Agents Chemother 2000;44:2569-71.

55. He YM, Lv XS, Ai ZL, Liu ZS, Qian Q, Sun Q, et al. Prevention and therapy of fungal infection in severe acute pancreatitis: a prospective clinical study. World J Gastroenterol 2003;9:2619-21.

56. Matsuno S, Ogawa M, Watanabe S, Atomi Y. National survey for the efficacy of blood purification therapy in severe acute pancreatitis in Japan. Annual report of the Research Committee of Intractable Diseases of the Pancreas. 1998. p. 36-41.

57. Inoue K, Hirota M, Kimura Y, Kuwata K, Ohmuraya M, Ogawa M. Further evidence for endothelin as an important mediator of pancreatic and intestinal ischemia in severe acute pancreatitis. Pancreas 2003;26:218-23.

58. Takeda K, Mikami Y, Fukuyama S, Egawa S, Sunamura M, Ishibashi $\mathrm{T}$, et al. Pancreatic ischemia associated with vasospasm in the early phase of human acute necrotizing pancreatitis. Pancreas 2005;30:40-9.

59. Takeda K, Matsuno S, Sunamura M, Kakugawa Y. Continuous regional arterial infusion of protease inhibitor and antibiotics in acute necrotizing pancreatitis. Am J Surg 1996;171:394-8.

60. Takeda K, Matsuno S, Ogawa M, Watanabe S, Atomi Y. Continuous regional arterial infusion (CRAI) therapy reduces the mortality rate of acute necrotizing pancreatitis: results of a cooperative survey in Japan. J Hepatobiliary Pancreat Surg 2001;8: 216-20.

61. Imaizumi H, Kida M, Nishimaki H, Okuno J, Kataoka Y, Kida Y, et al. Efficacy of continuous regional arterial infusion of a protease inhibitor and antibiotic for severe acute pancreatitis in patients admitted to an intensive care unit. Pancreas 2004;28:36973.

62. Anai H, Sakaguchi H, Uchida H, Matsuo N, Tanaka T, Yoshioka $\mathrm{T}$, et al. Continuous arterial infusion therapy for severe acute pancreatitis: correlation between CT arteriography and therapeutic effect. J Vasc Interv Radiol 1999;10:1335-42.

63. Hirota $\mathrm{M}$, Inoue $\mathrm{K}$, Kimura $\mathrm{Y}$, Mizumoto $\mathrm{T}$, Kuwata $\mathrm{K}$, Ohmuraya $\mathrm{M}$, et al. Non-occlusive mesenteric ischemia and its associated intestinal gangrene in acute pancreatitis. Pancreato$\operatorname{logy} 2003 ; 3: 316-22$. 